\title{
GETTING AN EDGE IN ENGINEERING EDUCATION
}

\author{
Jerry O’Connor, Dan G. Dimitriu \\ Physics, Engineering, and Architecture Department \\ San Antonio College
}

This paper is based on a work in progress, sponsored in part by the National Science Foundation, that was initiated to address the need for more college graduates who are prepared for careers in engineering, science, and technology related fields. The work involves a new program that was designed to increase high school students' awareness of and sustain their interest in the study of engineering and to provide them with the knowledge, skills, and confidence that will facilitate their completing a Bachelor's degree in engineering. We present here a description of the program and the results of the first run of the program during Summer 2003. Our plans for the second iteration in Summer 2004 are also outlined.

The problem of recruitment and retention of students in engineering programs is widely acknowledged and many solutions have been proposed. One solution that has been particularly successful is the San Antonio Pre-freshman Engineering Program (PREP), which was founded in 1979 as an attempt to motivate middle school students to begin studying for careers in science, engineering, and technology. The PREP program has been so successful over the last 24 years that it has been replicated at several other locations in Texas and other states. According to the program's website $1,90 \%$ of the students participating in the program have graduated from college, and $52 \%$ of those graduates majored in mathematics, science, or engineering. The most recent (2002) survey reported figures of $88 \%$ and $50 \%$ respectively ${ }^{2}$. Whether or not this small decline is part of a trend or simply the result of a statistical fluctuation, there are indications that these rates might be improved. Since students usually complete PREP by their first year in high school, there are still two more years in which their belief that they are capable of earning a Bachelor's degree in a STEM field could be reinforced ${ }^{3}$.

To bridge this apparent gap in reinforcement strategies, the new program was intended to provide a more continuous transition between students' completion of PREP and their first year in college. It would introduce these presumably academically advanced high school students to college level course work as a learning community and provide them with activities to develop independent learning and teamwork skills as well as a peer support structure. After the students graduate from high school they would be able to continue their studies in engineering as part of an ongoing Learning Community cohort at San Antonio College, and then transfer to a four year university to obtain a Bachelor's degree in engineering. The proven success of the PREP 
program and Learning Communities, in combination with a coordinated curriculum ${ }^{4}$, suggested great promise for this new program.

\section{$\underline{\text { Program Details }}$}

We named the program "Early Development of General Engineering” or EDGE. It was designed to take place during an eight week summer session at San Antonio College in 2003. A learning community (LC) of 20-25 tenth and eleventh grade high school students would be enrolled in two college courses: College Algebra and Introduction to Engineering. The two classes would meet from 9:00 AM to noon, Monday through Friday. Afternoon activities were to consist of supervised study (SS1) and student success (SS2) sessions from 1:00 to 4:00 pm. The SS1 sessions were to involve students working with each other in small sub-groups of approximately ten students from their larger Learning Community of 20-25. Each group was to have a leader/mentor that facilitated the students' learning activities. This would allow the students to work on some of their homework together, receive assistance with assignments, work on group projects, and build a sense of community and shared success. The SS1 Leaders would understand the purpose and function of Learning Communities and promote the value of collaborative learning and peer support, and receive formal training in group learning methods (similar to Supplemental Instruction) prior to the start of the program. The SS2 sessions were to be one-hour long and include the entire group, along with the SS1 Leaders. These sessions would include workshops on study techniques, test taking, guest speakers, and special presentations on topics pertaining to the field of engineering. There would also be four field trips scheduled to introduce students to engineering activities in two private companies, one agency, and one university in the local area.

Initially we expected to recruit most of the students for the program from a list of previous PREP participants, but widespread interest shown in the program prompted us to offer the program to all qualified students. One of the authors made presentations to counselors and students at several surrounding high schools, and the program was also announced in the local press and on our web site. Students were required to meet the same admission requirements as other collegelevel students, and paid only a \$25 entry fee. All other expenses were funded by the Alamo Community College District Foundation and the NSF grant (an Engineering Education Discretionary Grant ${ }^{4}$ ).

\section{Program Results}

Although there had been a strong positive response from students, teachers, and counselors to the program announcement and the presentations made at local high schools, a total of only thirty-two complete applications were received. Since this was the first year of the program, every effort was made to accommodate students who found out about the program late. Application deadlines and subsequent timelines for placement testing were moved back to compensate for the disparity in the timely reception of program information at some of the high schools. These delays created an uncomfortable level of uncertainty in the outcome of the placement tests, which were not completed until the week before the class was to begin.

Of the thirty-two applicants, only twenty met the standard college admission requirements, and of these, only seven scored high enough on the math placement test to enroll in College Algebra. This led to a modification of the original program design, and two different tracks were 
established. The seven high school students that qualified were enrolled in a section of College Algebra with 19 other regular college students, as well as the Introduction to Engineering course. The remaining 13 students were enrolled in the same Introduction to Engineering course and also participated in supervised learning activities in the Basic Skills Enrichment Program (BSEP). The Introduction to Engineering course also included 10 regular college students. This fragmentation of the learning community made it impossible to attain the desired level of cohesion during the afternoon study sessions. Another problem encountered was in finding and hiring a sufficient number of qualified SS1 leaders. Although these deviations in the implementation of the original program design seem likely to have made an adverse impact on the level of student achievement that we thought was possible, we were nevertheless encouraged by the final results. The distributions of final grades in each of the two courses are displayed in Tables 1 and 2 .

All twenty EDGE students received a productive grade and college credit for the Introduction to Engineering course, and their performance was commensurate with their college level classmates. It was noted by the instructor (Dimitriu), that the interaction between the high school and college students seemed to have a positive effect on both groups.

Table 1: Final Grades posted for Introduction to Engineering

\begin{tabular}{|ccccccc|}
\hline $\mathrm{A}$ & $\mathrm{B}$ & $\mathrm{C}$ & $\mathrm{D}$ & $\mathrm{F}$ & $\mathrm{W}$ & total \\
\hline 13 & 5 & 2 & 0 & 0 & 0 & 20 \\
$65 \%$ & $25 \%$ & $10 \%$ & $0 \%$ & $0 \%$ & $0 \%$ & EDGE Rates \\
18 & 9 & 3 & 0 & 0 & 0 & 30 \\
$60 \%$ & $30 \%$ & $10 \%$ & $0 \%$ & $0 \%$ & $0 \%$ & Course Rates \\
\hline
\end{tabular}

Three of the seven EDGE students enrolled in College Algebra received productive grades and three withdrew. Although the withdrawal of these students was a disappointment, the withdrawal rate for the EDGE group was considerably lower than it was for the entire class (43\% vs. 58\%). The productive grade rate (PGR) for the EDGE students was also 43\%, which again compares favorably with the PGR of $35 \%$ for the entire class.

Table 2: Final Grades posted for College Algebra

\begin{tabular}{|ccccccc|}
\hline $\mathrm{A}$ & $\mathrm{B}$ & $\mathrm{C}$ & $\mathrm{D}$ & $\mathrm{F}$ & $\mathrm{W}$ & total \\
\hline 2 & 1 & 0 & 1 & 0 & 3 & 7 \\
$29 \%$ & $14 \%$ & $0 \%$ & $14 \%$ & $0 \%$ & $43 \%$ & EDGE Rates \\
4 & 3 & 2 & 2 & 0 & 15 & 26 \\
$15 \%$ & $12 \%$ & $8 \%$ & $8 \%$ & $0 \%$ & $58 \%$ & Course Rates \\
\hline
\end{tabular}


The thirteen students who worked on basic skills enrichment were tested again at the end of the eight week program. Eight of these students scored high enough to raise their competency rating by at least one level. Two had higher scores, but not high enough to reach the next level, and three had the same or lower scores. Detailed results are shown in Table 3.

Table 3: Basic Math Skills Testing Results

\begin{tabular}{|cccc|}
\hline initial score & final score & change & $\%$ change \\
\hline 67 & 92 & 25 & $31.4 \%$ \\
54 & 67 & 13 & $21.5 \%$ \\
61 & 90 & 29 & $38.4 \%$ \\
54 & 75 & 21 & $32.6 \%$ \\
96 & 106 & 10 & $9.9 \%$ \\
90 & 90 & 0 & $0.0 \%$ \\
58 & 46 & -12 & $-23.1 \%$ \\
80 & 90 & 10 & $11.8 \%$ \\
68 & 83 & 15 & $19.9 \%$ \\
64 & 100 & 36 & $43.9 \%$ \\
60 & 56 & -4 & $-6.9 \%$ \\
\hline \multicolumn{5}{c}{ average math test gain: } \\
\hline
\end{tabular}

\section{Conclusions}

Although the number of students in the College Algebra group was very small, and the division of the entire group among the two tracks must have inhibited the development of a more effective learning community, the EDGE students as a group still achieved greater academic success overall than their college level classmates. The larger group of Basic Skills students also showed substantial gains: an increase of $16 \%$ in the average math test score and $62 \%$ of the students progressing by at least one skill level.

A survey administered at the end of the eight week period revealed that $86 \%$ of the College Algebra students and $92 \%$ of the Basic Skills students would recommend the EDGE Program to their peers. Even with the difficulties and limitations imposed by the novelty of the program, it has shown positive results. The increased awareness of the EDGE Program in surrounding high schools and our experience with this year's program suggest a greater level of success can be achieved in 2004. Our experience in 2003 indicated that there was a great deal of interest in the program expressed by students who had not participated in PREP, and there was a substantial number of PREP students who did not meet the testing requirement to enroll in College Algebra. This has prompted us to propose a dual-track program for 2004 that could be implemented in part or in its entirety. The first track will follow the original program concept, with students enrolled in Introduction to Engineering and College Algebra. This track will also remain 
identified as the EDGE program, and will be the only one advertised. The second track will be composed of Introduction to Engineering and a Computer Literacy course. Both tracks will provide 5 college credit hours upon successful completion. We anticipate approximately 100 applicants for the 2004 Program, of which we expect 25 students to qualify for College Algebra. If funding is available we would like to enroll another 25 in the second track.

The EDGE 2004 Program will be advertised through posters, mail-outs, press releases, and visits to local high schools. This year we are also making a concentrated effort to make contact with high school principals and district administrators to inform them of the program. We would like to hold an open house on our College campus to introduce students and their parents to our institution and to answer questions about the program. We would also like to hold a closing ceremony for the EDGE graduates similar to but on a smaller scale than what is done in the PREP Program. The expansion of the both the original program design as well as the marketing strategy is expected to allow us to enlist a larger number of high school students and increase their likelihood of choosing engineering as a potential career choice.

References:

1. www.texprep.org

2. from the 2003 PREP Closing Day Assembly Program

3. Gottfredson, L. S. (2002). Gottfredson's theory of circumscription, compromise, and self-creation. Pages 85-148 in D. Brown (Ed.), Career choice and development (4th ed.). San Francisco: Jossey-Bass.

4. Dan Dimitriu \& Jerry O'Connor, "Forging Stronger Ties Between Community Colleges and Four Year Universities", Proceedings of the 2004 American Society for Engineering Education Annual Conference \& Exposition

Biographical Information:

JERRY O'CONNOR has been teaching physics (and a few engineering courses) at San Antonio College since 1987. He was the Campus Coordinator for the Texas Alliance for Minority Participation program from 1993 to 2002, and is currently the Department Chairperson for Physics, Engineering, \& Architecture. He has been involved in numerous initiatives to integrate the findings of physics and engineering education research with education practice.

DAN G. DIMITRIU has been practicing engineering since 1970 and taught engineering courses concurrently for over 20 years. He has been involved with several engineering societies, most recently as vice-president of the SPECentral Texas Section. He has been the coordinator of the Engineering Program at San Antonio College since 2001. His research interests are: alternative fuels, fuel cells, plastics, and engineering education. 